\title{
Analysis of Application of Multimedia Technology in Martial Arts Teaching
}

\author{
Benlai Cui \\ Shangqiu University, Shangqiu Henan, 476113,China
}

Keywords: Multimedia technology, Martial arts, Teaching.

\begin{abstract}
Multimedia technology has very distinct characteristics and functions for teaching, these features and functions often do not have the traditional media. Martial arts education in the field of multimedia technology has good uses. It not only can greatly enrich martial arts teaching methods and means, but also to fully enhance the learner's initiative, and can effectively help educators to better enhance the effectiveness of teaching. In view of this, the introduction of multimedia technology in the martial arts education seems imminent. This paper describes the basic features of multimedia technology and martial arts techniques, discusses the technology used in multimedia teaching martial arts in specific methods for multimedia applications in the need for martial arts teaching, analysis of the real problems that exist in the current teaching martial arts and proposed.
\end{abstract}

\section{Introduction}

In view of the rapid development of modern science and technology, more and more teachers in the classroom teaching methods using high technology in the teaching process, and introducing multimedia technology into teaching is one of the typical. However, in the actual process of Martial arts teaching in, there are a large number of teachers are still using the original demonstration and explanation, imitation pedagogy. I think, more briefly in the teaching of martial arts moves, if teachers use traditional teaching methods is also able to easily complete the teaching task. However, once in the teaching of complex martial arts moves will greatly affect the efficiency of teaching. Teachers should not only on specific actions make meticulous explanations, but also from the viewpoint of the model, teaching the exercise intensity greatly, but also greatly enhance the difficulty of teachers ' classroom teaching, frustrating learning enthusiasm. If the application of multimedia technology to the classroom teaching of martial arts, will not only deepen the comprehensive understanding of learners for a specific martial arts action, but also to show the demonstration by the use of standardized teaching courseware, together with the related music, text, and audio narration, thereby actually reducing the number of demonstration teaching, enhance the learner's initiative, and can enhance the quality of teaching. It can be said that multimedia technology in the field of martial arts teaching is a very suitable means must be reasonable application of this measure, resulting in multimedia teaching and traditional teaching, the ideal way to combine.

\section{Basic features of multimedia technology and martial arts techniques}

The most obvious sign is a multimedia network technology and computer technology to produce more and more important role in the classroom teaching process. With the introduction of the internet, not only can effectively change inherent in teaching, but also causes the contents of teaching, there is a general morphology changes. For example, interactive learning computers would be revolutionized conventional teaching methods, the teaching focus from teaching into learning, so that learners' enthusiasm has been an unprecedented display, learners have truly become the main body of 
classroom teaching. Proper use of multimedia technology in teaching, but also be able to accurately analyze the relevant action to correct the wrong place learners in the learning process, so that the quality of classroom teaching have been fully upgraded, which is due to multimedia technology enables text, audio, video, and animation and other information, fully integrated, and comprehensive treatment to achieve the use of randomness and interactive practice.

Martial arts is a more difficult learning sports items, mainly due to its lack of technical operation of a certain periodicity, each action often contain different directions, Rack, methods, and so on for emotional and charm have quite a few requirements . Meanwhile, among the various martial arts action with a fast and slow, dynamic and static, rigid and flexible as well as a variety of virtual and real change, so as to allow mutual convergence between the various movements seem changeable. Teachers To truly teach martial arts, and no shortcuts can go. So, teaching martial arts in order to enhance the quality of classroom instruction, it must be a breakthrough in the teaching mode, by changing the effective teaching methods, and implement global standards. In order to be able to make the operation more standardized, it must focus on the exchange, analysis of means of prevention, once the teacher can only professor in the mouth, certainly can not be expected to practice teaching effectiveness, and martial arts action covers the jump, flash, soar, flutter, rolling and turning, and many other jumping class movement rotation, in the actual offense and defense will have a considerable risk.

\section{Necessity of multimedia application in martial arts teaching}

In the theoretical teaching of martial arts class, students tend to feel dull and learning initiative is generally not very high, and the effectiveness of teaching will naturally not be too good. Theory of educational psychology, classroom teaching content and methods of novelty and fun touches strong measures learner learning initiative. Therefore, the teacher can use in martial arts education multimedia courseware for teaching. This courseware should be equipped with a good interface for human-computer interaction and multimedia teachers teach content, combined with Visual images, video, or animation, which more accurately conveys the teacher's teaching content. This intuitive and vivid teaching method can effectively mobilize the enthusiasm of learners, so its various senses are stimulated simultaneously, so they can attract their attention; arouse their enthusiasm, enhancing the effectiveness of teaching.

In practice, teaching, technical characteristics of Martial arts class teaching of martial arts with some particularity. Classroom teaching should take the Visual presentation as main. Now, with the continued expansion of higher education, increase in the number of students attending colleges and universities, and physical education curriculum is class in the school playground, which disturbed quite a few of the factors, which for physical education teachers of demonstration and presentation proposed a new higher education requirements. Sports teachers in model and explained Shi, students does not must are enough understand clear, this on need in multiple points Shang tour model and explained, usually teaching a a action need spent many time, teaching of effectiveness also enough high, and in martial arts practice teaching and will due to gender, and age and fitness, factors to completed model sex action, also has part high difficulty action not only structure quite complex and need in is short of time within solution, in air movement Shi often to stay or slowed action of speed, Teachers cannot explain in a short demonstration period, where the students find it difficult to understand the trick. After using multimedia technology to make courseware can not only solve problems on how to choose a good demonstration of the position, but also can save many hours of demonstration and explanation, which helps teachers more time to be correct, and enhance the effectiveness of teaching. Meanwhile, once part of the structure of the model to a comprehensive display of martial arts moves, details, can use multimedia technologies, the lens is reasonable dispatch from various martial arts moves in terms of direction and distance, trajectory, etc. In this way, students can understand after watching video martial arts where wrong, nature also are a good way to correct errors made by its martial arts moves, and formed the right martial arts techniques to further improve the quality of classroom teaching of martial arts. 


\section{Practical problems existed in martial arts teaching at present}

First, the content of teaching martial arts is very boring. Martial Arts Instruction in university or application indoctrination in the classroom means of education in the past, that is, first by PE teachers demonstrate regulatory action, and then taught step by step, step by step and then practice by the students, and finally the overall operation training. Under this teaching method, students tend to be only a single teacher taught martial arts for exemplary action imitation, learning its own subjective position cannot be a good show, so the teaching methods cannot be effectively and efficiently mobilize from the learner's initiative, and it is likely to result in a considerable number of learners lose the enthusiasm to continue in-depth learning, and martial arts teachers often there are many deficiencies in the quality of their own, thus leading educational outcomes will be greatly inadequate.

Second, the theory of teaching martial arts content is very small. In Martial arts theory taught in the classroom teaching part, the vast majority of schools simply arrange several indoor theoretical courses at the beginning of learning to surface information of the origin of martial arts as well as various schools and other learners are taught, but in the subsequent classroom teaching process are generally direct the practice of martial arts training courses, martial arts teaching content related to the spirit of the martial arts to explain very little, even if the students learn the martial arts-related actions, but for martial Arts most important section, which is what's martial spirit absorb very little and, thus affecting the quality of teaching martial arts and learner performance.

Third, the actual needs of the martial arts teacher resources are not adapted to the martial arts teaching. In order to truly mobilize the learners' initiative, showing it has a subjective position, all schools were to spend a lot of effort to broaden the types of sports elective course, but in the physical education curriculum and not enough attention to the cultivation of talents of martial arts teacher. As a result, some in the actual teaching martial arts teachers not graduated from professional martial arts and their professional quality is not perfect. At the same time, there are some people in the martial arts education teachers for professional well versed in martial arts, but modern teaching methods, multimedia technology is not enough attention, or even simply do not understand, so that will naturally affect the martial arts school teaching better to carry out.

\section{Specific methods of multimedia technology applied in martial arts teaching}

\section{Methods of multimedia technology applied in martial arts theory teaching}

Use when Martial arts teachers may martial arts curriculum theory of Teaching in the implementation of 3D technology, POWER-POINT software, FLASH software and PHOTSHOP software to create fine courseware, plus to be able to attract students good interface to itself to be taught the content use of multimedia technology, and matched them with a vivid image of the pictures or videos, so as to put their content to be taught in a reasonable, comprehensive and accurate representation. Thus, it naturally can well mobilize the enthusiasm of learners. Of course, the use of modern multimedia courseware production technology can also facilitate students to carry out self-review or the like, but also deepen their understanding of the various types of knowledge.

\section{Methods of multimedia technology applied in martial arts practical teaching}

Martial arts has distinct characteristics determines its unique position different from other sports. Institutions of higher learning martial arts practice in the classroom teaching should focus on very intuitive, so we should take as the main presentation and demonstration. In the practice of martial arts teaching, there is the difficult part of the operation, not only the structure is very complex and still needs to be completed in a very short space of time, for example, and other vacated flying kick and cyclone leg action is. In this case, martial arts teacher is often difficult to be comprehensive in the demonstration, clear and precise explanations, and after the demonstration to explain when, some students often still hear enough to understand. After the application of multimedia technology related to the production of courseware, not only can save a lot of demonstrations and to explain the action 
essentials particular time, so that teaching workers to have more ample time to correct errors made by learners for action. At the same time, once the operation is difficult to demonstrate its exemplary details of the martial arts action, you can use the advantages of multimedia technology, allowing students to observe in detail from all angles without martial arts action. In the case of qualified. Also the introduction of this new high-speed imaging technology to be very gentle with the performance of state action is happening in a short time, so that can be a good way to break the limitations of space and time produced.

\section{Methods of multimedia technology applied in martial arts techniques}

In the process of the implementation of special training in martial arts, for learners to master the art movement should start from the generalization, gradually differentiation, coupled with progressive consolidation until the action can go. Learners learn new martial arts movements are usually made from the action imitate teachers started. However, at this stage among the students of the martial arts action sense of time and sense of space they are usually quite poor, there will be a lot of mistakes so that you do do. Once the introduction of multimedia technology, learners can train themselves fully to shoot a scene, which they then use multimedia technology to complete the action to be played back, and to compare with the standardized operation, so that it can be a good teacher to say its shortcomings, it can help them quickly correct their mistakes, and accurately grasp the action as soon as possible.

\section{Conclusions}

Overall, combining martial arts teaching and multimedia technology is China's current stage of sports educational reform emerged in the new teaching methods in the classroom, one of the new changes in the relationship between teachers and students, from the previous teacher-led martial arts education completely converted into student-oriented education. Multimedia teaching method in physical education is not able to really become an important form of, with an emphasis on physical educators can reach the information literacy competency standards. So, physical educators must go, to enhance their competence and in particular to strengthen the cultivation of the information quality, so as to upgrade their professional standards, to be more reasonable and accurate use of multimedia technology to teaching. Different types of media, all have their roles and characteristics, only reasonable use, to maximize the effectiveness of classroom teaching and learning. So, the school physical education teachers should be better used to show different characteristics of various types of media content, so as to strive to achieve maximum effectiveness.

\section{References}

[1] Ma Yongjun. Martial arts multimedia video technology teaching experimental research, Journal of Capital Institute of Physical Education, 2009(3).

[2] Chen Shuru. The application of multimedia CAI technology in martial arts teaching, Neijiang Science and Technology, 2009(6).

[3] Xia Yishan, Zhong Shangyou. The application of multimedia CAI technology in martial arts teaching and thinking, Hubei Sports Techonology, 2010(2).

[4] Du Shougao, Lv Wei. Application of multimedia technology in martial arts teaching analysis, Sports scientific literature, 2010(12).

[5] Ding Lingling. Multimedia technology is applied to the value of martial arts teaching teenagers, Contemporary Sports Technology, 2013(16). 